\title{
Research
}

Tim A Holt, Tina D Hunter, Candace Gunnarsson, Nada Khan, Paul Cload and Gregory YH Lip

\section{Risk of stroke and oral anticoagulant use in atrial fibrillation:}

\author{
a cross-sectional survey
}

\begin{abstract}
\section{Background}

Oral anticoagulants substantially reduce the risk of stroke in atrial fibrillation but are underutilised in current practice.
\end{abstract}

\section{Aim}

To measure the distribution of stroke risk in patients with atrial fibrillation lusing the $\mathrm{CHADS}_{2}$ and $\mathrm{CHA}_{2} \mathrm{DS}_{2}$-VASc scores) and changes in oral anticoagulant use during 2007-2010.

\section{Design and setting}

Longitudinal series of cross-sectional survey in 583 UK practices linked to the QResearch ${ }^{\circledR}$ database providing 99351 anonymised electronic records from people with atrial fibrillation.

\section{Method}

The proportion of patients in each $\mathrm{CHADS}_{2}$ and $\mathrm{CHA}_{2} \mathrm{DS}_{2}-\mathrm{VASc}$ risk band in 2010 was calculated; for each of the years 2007-2010, the proportions with risk scores $\geq 2$ that were using anticoagulants or antiplatelet agents were estimated. The proportions identified at high risk were re-estimated using alternative definitions of hypertension based on coded data. Finally, the prevalence of comorbid conditions in treated and untreated high-risk $\left(\mathrm{CHADS}_{2} \geq 2\right)$ groups was derived.

\section{Results}

The proportion at high risk of stroke in 2010 was $56.9 \%$ according to the $\mathrm{CHADS}_{2} \geq 2$ threshold, and $84.5 \%$ according to $\mathrm{CHA}_{2} \mathrm{DS}_{2}-\mathrm{VASc} \geq 2$ threshold. The proportions of these groups receiving anticoagulants were $53.0 \%$ and $50.7 \%$ respectively and increased during 2007-2010. The means of identifying the population of individuals with hypertension significantly influenced the estimated proportion at high risk. Comorbid conditions associated with avoidance of anticoagulants included history of falls, use of nonsteroidal anti-inflammatory drugs, and dementia

\section{Conclusion}

Oral anticoagulant use in atrial fibrillation has increased in UK practice since 2007, but remains suboptimal. Improved coding of hypertension is required to support systematic identification of individuals at high risk of stroke and could be assisted by practice-based software.

\section{Keywords}

anticoagulants; atrial fibrillation; electronic health records; primary health care; stroke.

\section{INTRODUCTION}

Atrial fibrillation (AF) is the commonest disorder of heart rhythm and an important risk factor for thromboembolic stroke. ${ }^{1}$ An individual's risk of stroke can be estimated using risk-stratification schemes that have been validated in various studies. ${ }^{2-5}$ In Europe, the $\mathrm{CHADS}_{2}$ and $\mathrm{CHA}_{2} \mathrm{DS}_{2}{ }^{-}$ VASc scores are recommended (Box 1). ${ }^{6} \mathrm{CHA}_{2} \mathrm{DS}_{2}$-VASc is significantly more inclusive of common stroke risk factors, while $\mathrm{CHADS}_{2}$ is simpler, easier to remember, and was proposed over 10 years ago, so has tended to be used more extensively in clinical practice. However, the limitations of the $\mathrm{CHADS}_{2}$ score have been highlighted recently. ${ }^{7.8}$ The $\mathrm{CHA}_{2} \mathrm{DS}_{2}$ VASc score is more effective at identifying the 'truly low-risk' population where (in patients with a $\mathrm{CHA}_{2} \mathrm{DS}_{2}$-VASc score $=0$ no thromboprophylaxis is needed. ${ }^{9}$ For the higher-risk groups, oral anticoagulation significantly reduces the risk of stroke and mortality. ${ }^{10}$

Decisions over anticoagulation need to be tailored to the individual. However suboptimal use and uptake in $A F$ is a global phenomenon. ${ }^{11-13}$ Opportunities are thereby missed to impact significantly on an important cause of cardiovascular morbidity and mortality.

Surveys of stroke risk in AF based on UK primary care data have been published

TA Holt, PhD MRCP FRCGP, Academic Clinical Lecturer; N Khan, PhD, research fellow, Department of Primary Care Health Sciences, Oxford University, Oxford. TD Hunter, PhD, honorary senior researcher, Department of Primary Care Health Sciences, Oxford University, Oxford; executive director of outcomes research, S2 Statistical Solutions, Cincinnati, OH C Gunnarsson. PhD, president S2 Statistical Solutions, Cincinnati, OH. P Cload, PhD, Global Head of Cardiology \& General Medicine, Global Marketing Organisation, GE Healthcare, Chalfont St Giles. GYH Lip, MD, FRCP, DFM, FACC, FESC Professor of Cardiovascular Medicine, University of Birmingham Centre for Cardiovascular Sciences, previously. ${ }^{14-16}$ The authors were interested not only in the patterns of risk and levels of anticoagulant use, but also in the ability of primary care data to support risk estimation. A software tool (GRASP-AF Guidance on Risk Assessment and Stroke Prevention in Atrial Fibrillation) has been developed for UK general practices ${ }^{17}$ which produces lists of high-risk but untreated individuals. The success of this approach depends on the data quality of the source systems, including the disease registers.

Specifically, the hypertension register is problematic. Clinicians may not always enter a hypertension code if the person is already on another disease register that has a blood pressure target. To do so may duplicate the processes of recall. For those with AF, exclusion of a patient with hypertension from the hypertension register runs the risk of underestimating stroke risk and of failing to identify the need for anticoagulation. While administrative registers may be useful for estimating the prevalence of hypertension at population level, ${ }^{18,19}$ their adequacy for supporting estimation of stroke risk has not been confirmed.

This study used the QResearch ${ }^{\circledR}$ database to determine the distribution of $\mathrm{CHADS}_{2}$ and $\mathrm{CHA}_{2} \mathrm{DS}_{2}$-VASc scores and changes in prescribing of oral anticoagulant and antiplatelet agents during the years 2007-

\section{City Hospital, Birmingham.}

\section{Address for correspondence}

Tim A Holt, Oxford University, Department of Primary Care Health Sciences, Radcliffe Observatory Quarter, Woodstock Road, Oxford, OX2 6GG

E-mail: tim.holtaphc.ox.ac.uk

Submitted: 28 March 2012; Editor's response: 18 April 2012; final acceptance: 28 May 2012. (c)British Journal of General Practice

This is the full-length article (published online 1 Oct 2012) of an abridged version published in print. Cite this article as: Br J Gen Pract 2012; DOI: 10.3399/bjgp12X656856 


\section{How this fits in}

Suboptimal use of oral anticoagulants in patients with atrial fibrillation is a missed opportunity to impact on an important cause of thromboembolic stroke. Systematic identification of those at high stroke risk requires consistent recording of risk factors during routine care. About one in seven will currently be missed if inclusion in the hypertension register is used to determine hypertensive status, highlighting the need for improved recording of hypertension in this group. A number of barriers must be overcome to optimise the safe and effective use of anticoagulants for stroke prevention in patients with atrial fibrillation.

2010, following publication of a National Institute for Health and Clinical Excellence (NICE) guideline on AF. ${ }^{20}$ This was the prevailing guideline for the period of the study. The impact on numbers identified of alternative definitions of hypertension was investigated. The study also measured the differences between treated and untreated populations in the prevalence of a range of prespecified comorbidity codes potentially relevant to anticoagulant prescribing.

\section{METHOD}

\section{Source of data}

The QResearch database contains anonymous electronic data from over 600 UK practices. Records in this database from people with a diagnosis of AF were identified. Individual records were excluded if the person had been registered for less than 12 months, or was a temporary resident.

\section{Box 1. $\mathrm{CHADS}_{2}$ and $\mathrm{CHA}_{2} \mathrm{DS}_{2}$-VASc risk scores}

Unless indicated otherwise, 1 point is allocated to each risk factor $\mathrm{CHADS}_{2}$ (maximum 6 points)

C Congestive heart failure

H Hypertension

A Age $>75$ years

D Diabetes

S Stroke, transient ischaemic attack (TIA), or other thromboembolism history (2 points)

\section{$\mathrm{CHA}_{2} \mathrm{DS}_{2}-\mathrm{VASc}$ (maximum 9 points)}

\section{Congestive heart failure}

H Hypertension

A Age $>75$ years (2 points)

D Diabetes

S Stroke, TIA, or other thromboembolism history (2 points)

V Vascular disease (coronary artery or peripheral vascular disease)

A Age 65-74 years

Sc Sex category (female 1 point, male 0 points)

People with a $\mathrm{CHADS}_{2}$ score of 2 or higher are recommended anticoagulation unless contraindicated. Those with $\mathrm{CHADS}_{2}$ score less than 2 can be assessed using $\mathrm{CHA}_{2} \mathrm{DS}_{2}-V A S c$. Those with $\mathrm{CHA}_{2} \mathrm{DS}_{2}-\mathrm{VASc}=0$ require no thromboprophylactic therapy.
No other exclusion criteria were applied, and all available eligible records were included in the study. QResearch has been validated using other nationally published sources, as broadly representative of the UK population. ${ }^{21}$

\section{Statistical methods}

Analyses were carried out using STATA (version 11) and SAS (version 9.2). The $\chi^{2}$ test was used to measure differences in proportions and to calculate $P$-values for significance.

\section{Cross-sectional surveys}

For each identified record, a stroke risk score was carried out using the $\mathrm{CHADS}_{2}$ and $\mathrm{CHA}_{2} \mathrm{DS}_{2}$-VASc algorithms. For each risk band, the proportion currently treated with anticoagulants or antiplatelet drugs was derived, based on the presence of a prescription for the drug in the record in the last 6 months. This cross-sectional survey was repeated for each of the years 2007 to 2010. The main outcomes of the study used the most recent (2010) cross-section.

\section{Influence of different definitions of hypertension}

The cross-sectional surveys required a coded diagnosis of hypertension for the risk score, and a range of Read Codes were used, similar to those supporting the Quality and Outcomes Framework (QOF). ${ }^{22}$ These are all 'child' codes of the G2 Read Code group. More inclusive means of identifying the population of individuals with hypertension (Box 2) were then used, based on use of antihypertensive medication and blood pressure values. The most recent cross-sectional survey (for 2010) was repeated using these alternative definitions, to measure the impact on the numbers identified.

\section{Comorbidity codes associated with lack of use of anticoagulation}

The prevalence of a range of comorbidity codes was examined in the treated and untreated high-risk populations recommended anticoagulation; $\chi^{2}$ tests were used to measure the significance of differences in prevalence.

\section{RESULTS}

The sample included 583 UK practices, and 99351 patient records. Of these, 59804 were available for the main cross-section of 1 October 2010; the remainder had died, left the practice, or were in a practice whose most recent data upload was before 1 October 2010. Table 1 gives the patient 


\section{Box 2. Definitions of hypertension based on primary care data (details available from the authors)}

Definition A: Requires a specific G2 Read code for hypertension, as in the Quality and Outcomes Framework (QOF)

Definition B: As for A, but includes also those with no specific hypertension code, but using an antihypertensive agent

Definition C: As for B, but excludes those with no hypertension code that have another possible reason for using an antihypertensive agent (for example, coronary heart disease if taking a calcium channel blocker, heart failure if taking an angiotensin-converting enzyme inhibitor

Definition D: $\quad$ As for $C$, but includes also those with evidence for hypertension based on recorded blood pressure values (mean of the last three measurements if available $\geq 150 \mathrm{mmHg}$ systolic or $\geq 90 \mathrm{mmHg}$ diastolic, even for another possible reason) or those not on treatment for hypertension but with blood pressure $\geq 160 \mathrm{mmHg}$ systolic or $\geq 100 \mathrm{mmHg}$ diastolic

For the main cross-sectional surveys 2007-2010, definition A was used.

characteristics for the 2010 cross-section. The median age in 2010 was 80.0 years with interquartile range 71.0 to 87.0 years. The median age at AF diagnosis was 73.0 years.

Table 2 shows the distribution of risk for the main survey of 2010 and the proportions treated with anticoagulants, antiplatelet agents, or both. An estimated $56.9 \%$ of people with $\mathrm{AF}$ had a $\mathrm{CHADS}_{2}$ score $\geq 2$, and $84.5 \%$ had a $\mathrm{CHA}_{2} \mathrm{DS}_{2}$-VASc score 22. Only $53.0 \%$ and $50.7 \%$ of these groups respectively were using oral anticoagulants, with the majority of the remainder receiving an antiplatelet agent.

\section{Table 1. Characteristics of the population with atrial fibrillation (AF)}

\begin{tabular}{|c|c|c|}
\hline & \multicolumn{2}{|c|}{ Total population with AF, $n=99351$} \\
\hline & Median & Interquartile range \\
\hline \multicolumn{3}{|l|}{ Age, years } \\
\hline At AF diagnosis & 73.0 & 64.0 to 81.0 \\
\hline In 2010 (of 69762 registered in 2010) & 80.0 & 71.0 to 87.0 \\
\hline \multicolumn{3}{|l|}{ Registration history, months } \\
\hline Prior to AF diagnosis & 146.3 & 31.1 to 283.3 \\
\hline \multirow[t]{2}{*}{ Total } & 222.8 & 111.3 to 355.7 \\
\hline & Count & $\%$ of $n$ \\
\hline \multicolumn{3}{|l|}{ Age group at AF diagnosis, years } \\
\hline$<50$ & 6721 & 6.8 \\
\hline $50-64$ & 19696 & 19.8 \\
\hline $65-74$ & 27769 & 28.0 \\
\hline$\geq 75$ & 45165 & 45.5 \\
\hline \multicolumn{3}{|l|}{ Age group in 2010 , years } \\
\hline$<50$ & 3096 & 3.1 \\
\hline $50-64$ & 10629 & 10.7 \\
\hline $65-74$ & 19215 & 19.3 \\
\hline$\geq 75$ & 66411 & 66.8 \\
\hline \multicolumn{3}{|l|}{ Sex } \\
\hline Male & 52527 & 52.9 \\
\hline Female & 46824 & 47.1 \\
\hline \multicolumn{3}{|l|}{ Current status of patient } \\
\hline Died & 20729 & 20.9 \\
\hline Left practice & 9205 & 9.3 \\
\hline Currently registered & 69417 & 69.9 \\
\hline
\end{tabular}

Table 3 and Figure 1 report the changes in numbers identified and proportions treated for the years 2007-2010. The proportion with $\mathrm{CHADS}_{2}$ score $\geq 2$ remained stable and use of anticoagulants in this group increased from $49.7 \%$ in 2007 to $53.0 \%$ in $2010(P<0.001)$.

Table 4 gives the numbers identified in each risk band, according to the alternative definitions of hypertension A-D for the 2010 cross-section only. Definition A requires a G2 Read Code for hypertension and is the basis for the estimated $56.9 \%$ of AF patients with $\mathrm{CHADS}_{2} \geq 2$ in 2010. This figure rises to $67.2 \%$ using definition $B$ lwhich also includes people with no $\mathrm{G} 2$ code but taking an antihypertensive drug). When those with a possible alternative reason to be taking the drug, such as heart failure or angina (definition C), are removed, the proportion is $65.9 \%$. Adding to this, people who do not have a coded diagnosis of hypertension but do have evidence of raised blood pressure (definition D), the figure is $66.1 \%$.

Table 5 gives the prevalence of relevant comorbidity codes in the treated and untreated populations for those recommended anticoagulants according to the $\mathrm{CHADS}_{2} \geq 2$ threshold, and the significance estimates for the differences. The difference is significant for most comorbidity codes, but those particularly relevant for clinical practice include a history of falls, peptic ulceration, and other upper gastrointestinal (GI) tract disorders: use of drugs for dyspepsia; and use of nonsteroidal anti-inflammatory drugs. These may be associated with avoidance of oral anticoagulation therapy.

\section{DISCUSSION}

\section{Summary}

Only $53.0 \%$ of patients in the study at high risk of stroke were using oral anticoagulants. This proportion increased only slightly in the years 2007-2010. At the same time, higher than expected usage was found in the low-risk groups: $32.1 \%$ of people with $\mathrm{CHADS}_{2}=0$ and $23.0 \%$ with $\mathrm{CHA}_{2} \mathrm{DS}_{2} \mathrm{VASc}=0$. While anticoagulation may be appropriate for some of these individuals (for example, those with valvular disease), this suggests that use of these algorithms has still to become established. $\mathrm{CHADS}_{2}$ was first proposed over a decade ago, while $\mathrm{CHA}_{2} \mathrm{DS}_{2}$-VASc was introduced much more recently.

The estimated high-risk population increases when more inclusive definitions of hypertension are used. The authors considered the safest to be ' $C$ ', which increases the proportion identified from 


\begin{tabular}{|c|c|c|c|c|}
\hline Risk band & $\begin{array}{c}\text { Proportion of AF } \\
\text { population } \\
\text { identified (\%) }\end{array}$ & $\begin{array}{l}\text { Proportion of the } \\
\text { risk band using } \\
\text { anticoagulants }(\%)\end{array}$ & $\begin{array}{c}\text { Proportion receiving } \\
\text { an antiplatelet } \\
\text { agent }(\%)\end{array}$ & $\begin{array}{c}\text { Proportion receiving } \\
\text { neither }(\%)\end{array}$ \\
\hline \multicolumn{5}{|l|}{$\mathrm{CHADS}_{2}$} \\
\hline 0 & 16.8 & 32.1 & 30.1 & 41.7 \\
\hline 1 & 26.3 & 46.0 & 40.2 & 18.9 \\
\hline 2 & 28.5 & 50.8 & 41.7 & 13.1 \\
\hline 3 & 15.2 & 56.1 & 40.7 & 10.3 \\
\hline 4 & 9.6 & 54.5 & 45.0 & 8.4 \\
\hline 5 & 3.2 & 54.4 & 43.7 & 8.8 \\
\hline 6 & 0.5 & 52.6 & 47.0 & 9.3 \\
\hline$\geq 2$ & 56.9 & 53.0 & 42.2 & 11.3 \\
\hline \multicolumn{5}{|c|}{$\mathrm{CHA}_{2} \mathrm{DS}_{2}-\mathrm{VASc}$} \\
\hline 0 & 6.1 & 23.0 & 18.5 & 61.2 \\
\hline 1 & 9.4 & 36.4 & 31.7 & 35.6 \\
\hline 2 & 14.6 & 47.2 & 37.6 & 20.2 \\
\hline 3 & 20.5 & 50.6 & 40.0 & 14.8 \\
\hline 4 & 21.3 & 50.3 & 42.9 & 12.5 \\
\hline 5 & 14.7 & 52.9 & 43.7 & 10.5 \\
\hline 6 & 8.7 & 53.2 & 46.2 & 8.5 \\
\hline 7 & 3.7 & 51.7 & 47.4 & 8.4 \\
\hline 8 & 1.0 & 53.8 & 45.6 & 8.3 \\
\hline 9 & 0.2 & 47.6 & 55.3 & 7.8 \\
\hline$\geq 2$ & 84.5 & 50.7 & 42.0 & 13.4 \\
\hline
\end{tabular}

Table 3. Trends in prescribing of anticoagulants in those with $\mathrm{CHADS}_{2} \geq 2$ and $\mathrm{CHA}_{2} \mathrm{DS}_{2}-\mathrm{VASC} \geq 2,2007-2010^{\mathrm{a}}$

\begin{tabular}{lcccc} 
& $\mathbf{2 0 0 7}$ & $\mathbf{2 0 0 8}$ & $\mathbf{2 0 0 9}$ & $\mathbf{2 0 1 0}$ \\
\hline Size of sample with atrial fibrillation & 62146 & 64524 & 63533 & 59804 \\
\hline Number identified with CHADS $2 \geq 2$ & 34827 & 36394 & 35948 & 34041 \\
\hline Percentage with CHADS $2 \geq 2$ & 56.0 & 56.4 & 56.6 & 56.9 \\
\hline Proportion, \% & & & & \\
Anticoagulant & 49.7 & 50.3 & 51.2 & 53.0 \\
Antiplatelet & 43.9 & 43.8 & 43.4 & 42.2 \\
Both & 6.0 & 6.3 & 6.5 & 6.5 \\
Neither & 12.4 & 12.1 & 11.9 & 11.3 \\
\hline Number identified with $\mathrm{CHA}_{2} \mathrm{DS}_{2}$ VASc $\geq 2$ & 52668 & 54526 & 53781 & 50547 \\
\hline Percentage with $\mathrm{CHA}_{2} \mathrm{DS}_{2}-\mathrm{VASC}_{2} \geq 2$ & 84.7 & 84.5 & 84.7 & 84.5 \\
\hline Proportion, \% & & & & \\
Anticoagulant & 48.0 & 48.7 & 49.3 & 50.7 \\
Antiplatelet & 42.9 & 43.2 & 42.9 & 42.0 \\
Both & 5.7 & 6.0 & 6.2 & 6.1 \\
Neither & 14.7 & 14.1 & 13.9 & 13.4 \\
\hline${ }^{a}$ Changes in the proportions treated with anticoagulants were all significant at the $\mathrm{P}<0.01$ level. &
\end{tabular}

$56.9 \%$ to $65.9 \%$. The additional inclusion of those with raised blood pressure levels (definition D) may be unreliable, particularly given the recent emphasis on home, rather than office-based measurements for diagnosis. ${ }^{23}$ About one in seven people at high risk of stroke $\left(\mathrm{CHADS}_{2} \geq 2\right)$ will have their risk estimated as $\mathrm{CHADS}_{2}=1$ and therefore not be recognised as requiring anticoagulant therapy by this decision rule if the presence of a code for hypertension (G2) is required to confirm hypertensive status. Improved coding of hypertension in primary care could readily be assisted by practice-based software.

Certain comorbidity codes were found to be more prevalent in the records of untreated compared with treated people in the $\mathrm{CHADS}_{2} \geq 2$ population. This analysis is observational and needs to be interpreted 


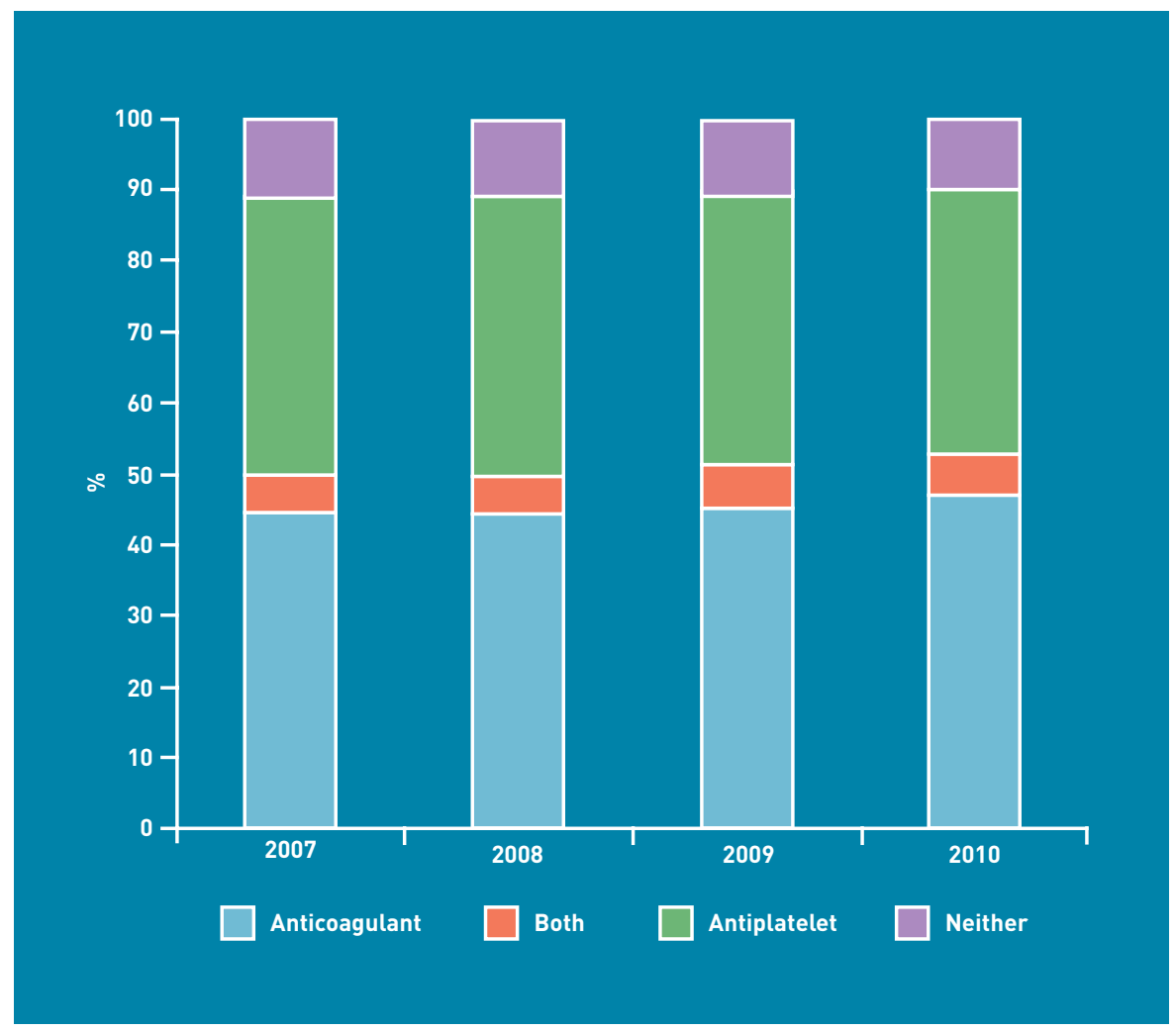

Figure 1. Trends in prescribing of anticoagulants in those with $\mathrm{CHADS}_{2} \geq 2,2007-2010$.

with caution. The increased recording of adverse reactions to anticoagulants in the treated population may reflect the fact that such recording only occurs in people exposed to treatment and that this does not always require withdrawal of the drug. Similarly, the recording of a bleeding tendency may be noted as a result of treatment and is more common in the treated population. Alcohol overuse and chronic liver disease do not, perhaps surprisingly, appear to be barriers to anticoagulation, but other findings confirmed previously suspected obstacles, including a history of falls. Each person needs to be assessed individually, as some are at much higher risk from this than

\section{Table 4. Influence of alternative definitions of hypertension on the numbers identified as requiring anticoagulation for the latest survey, $2010^{\circ}$}

\begin{tabular}{|c|c|c|c|c|}
\hline \multirow[b]{3}{*}{ Definition } & \multicolumn{4}{|c|}{$\begin{array}{l}\text { Number identified and proportion of } \\
\text { total AF population in } 2010(n=59804)\end{array}$} \\
\hline & \multicolumn{2}{|c|}{$\mathrm{CHADS}_{2} \geq 2$} & \multicolumn{2}{|c|}{$\mathrm{CHA}_{2} \mathrm{DS}_{2}-\mathrm{VASC} \geq 2$} \\
\hline & $n$ & $\%$ & $n$ & $\%$ \\
\hline A & 34041 & 56.9 & 50547 & 84.5 \\
\hline$B$ & 40178 & 67.2 & 53110 & 88.8 \\
\hline C & 39417 & 65.9 & 53022 & 88.7 \\
\hline D & 39544 & 66.1 & 53066 & 88.7 \\
\hline
\end{tabular}

others, but the risk from falls (compared to the benefits of anticoagulation) may be overestimated by clinicians managing people with AF and at risk of stroke. ${ }^{24}$ Drugs for dyspepsia are used more commonly in untreated individuals, who are also more likely to have a record of peptic ulcer or other upper Gl disorders. Whether this history is a sufficient basis for avoidance is again an individual matter, and may depend on how recently the upper Gl pathology occurred. The present survey also suggests avoidance of anticoagulants in people using nonsteroidal anti-inflammatory drugs, which interact with warfarin but are not an absolute contraindication in most cases. Those with dementia may be less able to concur with treatment and monitoring, and less able to consent to treatment, so in some cases avoidance in such people may be appropriate. Stroke is more often disabling than fatal, and individuals vary widely in their anticipated quality of life utility associated both with stroke and with antithrombotic therapies. ${ }^{25,26}$

Use of anticoagulants in the $\mathrm{CHADS}_{2}$ and $\mathrm{CHA}_{2} \mathrm{DS}_{2}$-VASc risk groups above the level of 2 tends to level off rather than increase with stroke risk (Table 2). This may imply that comorbidity itself offsets rather than increases the tendency to prescribe. Those at highest risk of thromboembolism are also at highest risk of bleeding complications, a fact that may influence clinicians. Haemorrhages related to warfarin are a significant problem and may be more common in 'real-world' practice $^{27}$ than under the more careful monitoring arrangements of randomised trials. ${ }^{28}$ Despite this, the risk-benefit ratio is particularly in favour of anticoagulant therapy in the higher-risk groups, ${ }^{29}$ provided it is carefully monitored.

\section{Strengths and limitations}

This is a large survey of a representative population of people with AF diagnosed and managed in both primary and secondary care settings. It includes people with all forms of AF, including both paroxysmal as well as chronic AF. The study may have not detected some individuals receiving anticoagulant prescriptions in secondary care. The National Patient Safety Agency has emphasised the importance of good communication between different bodies sharing responsibility for prescribing potentially interacting medication, ${ }^{30}$ and this has increased the use of codes in primary care to maintain awareness of anticoagulant therapy prescribed elsewhere. Identifying people taking both 


\section{Funding}

The study was funded by GE Healthcare (reference number 2580270919).

\section{Ethics committee}

QResearch studies are ethically approved by Trent MREC 03/04/021.

\section{Provenance}

Freely submitted; externally peer reviewed.

Competing interests

Paul Cload was an employee of GE Healthcare during this project. Candace Gunnarsson had financial support from GE Healthcare for the study. There are no other competing interests.

\section{Acknowledgements}

We acknowledge the contribution of EMIS practices who contribute to QResearch, the University of Nottingham, and EMIS for establishing, developing, and supporting the database and supplying the data for this research project.

\section{Discuss this article}

Contribute and read comments about this article on the Discussion Forum: http://www.rcgp.org.uk/bjgp-discuss

\section{Table 5. Prevalence of comorbidity codes in the anticoagulant treated and untreated populations of those in whom anticoagulation is recommended by $\mathrm{CHADS}_{2} \geq 2,(n=34041)$}

\begin{tabular}{|c|c|c|c|c|}
\hline & \multicolumn{3}{|c|}{$\begin{array}{l}\text { Prevalence of the comorbidity code in the } \\
\text { population in which anticoagulation } \\
\text { is recommended according to } \mathrm{CHADS}_{2} \geq 2(\%)\end{array}$} & \\
\hline & $\begin{array}{l}\text { Overall, } \\
n=34041\end{array}$ & $\begin{array}{l}\text { Treated group, } \\
\qquad n=18042\end{array}$ & $\begin{array}{l}\text { Untreated } \\
\text { group, } \\
n=15999\end{array}$ & $P$-value \\
\hline Haemorrhagic stroke or intracranial haemorrhage & 2.0 & 1.2 & 3.0 & $<0.001$ \\
\hline Post-traumatic intracranial haemorrhage & 0.2 & 0.1 & 0.4 & $<0.001$ \\
\hline Allergy to warfarin/other anticoagulants & 1.8 & 2.4 & 1.2 & $<0.001$ \\
\hline History of GI tract bleeding & 5.4 & 4.3 & 6.6 & $<0.001$ \\
\hline Uncontrolled blood pressure & 80.0 & 79.2 & 80.9 & $<0.001$ \\
\hline Bleeding tendency & 2.5 & 2.7 & 2.3 & 0.013 \\
\hline History of other bleeding & 13.6 & 15.2 & 11.8 & $<0.001$ \\
\hline History of bruising & 2.2 & 2.2 & 2.2 & 0.80 \\
\hline Falls & 4.7 & 3.2 & 6.3 & $<0.001$ \\
\hline Other significant injury & 37.2 & 34.7 & 39.9 & $<0.001$ \\
\hline Peptic ulceration and other upper GIT disorders & 30.9 & 28.9 & 33.1 & $<0.001$ \\
\hline GIT malignancy - at any time & 2.8 & 2.3 & 3.4 & $<0.001$ \\
\hline GIT malignancy - 1 October 2005 or later & 1.5 & 1.2 & 1.8 & $<0.001$ \\
\hline Other malignancy - at any time & 17.0 & 16.2 & 17.9 & $<0.001$ \\
\hline Other malignancy - 1 October 2005 or later & 10.9 & 10.5 & 11.4 & 0.006 \\
\hline Liver dysfunction/disease & 5.2 & 5.3 & 5.1 & 0.53 \\
\hline Chronic kidney disease & 2.0 & 2.0 & 2.1 & 0.81 \\
\hline Anaemia & 13.7 & 11.9 & 15.9 & $<0.001$ \\
\hline Alcohol abuse ${ }^{b}$ & 11.0 & 11.8 & 10.1 & $<0.001$ \\
\hline Epilepsy & 2.1 & 1.9 & 2.2 & 0.033 \\
\hline Terminal illness & 0.2 & 0.2 & 0.3 & 0.042 \\
\hline Dementia & 1.1 & 0.6 & 1.7 & $<0.001$ \\
\hline Drugs used for dyspepsia & 40.7 & 34.9 & 47.3 & $<0.001$ \\
\hline Anti-inflammatory drugs & 27.8 & 23.6 & 32.5 & $<0.001$ \\
\hline
\end{tabular}

anticoagulants and antiplatelet agents is difficult in surveys of this kind, because a person changing from one treatment to the other may have evidence of both in their recent record and this proportion may be slightly overestimated. The prevalence of falls in the population with AF is higher than reported in this study because a limited code set was used to identify them. A limited set of 'chronic kidney disease' codes was chosen in order to identify those with more significant forms of renal disease.

\section{Comparison with existing literature}

The findings of this study support other studies reporting suboptimal uptake of oral anticoagulants in AF. ${ }^{11}$ The figure for the proportion of individuals with $\mathrm{CHADS}_{2} \geq 2$ treated with oral anticoagulants (53\%) is very similar to that derived from a Canadian study published in 2011. ${ }^{13}$ This study has confirmed the lower usage in people with a history of falls, and those with dementia, previously reported in 2008. ${ }^{15}$

Implications for practice and research There is still huge potential for reducing the stroke risk of the population with AF by identifying people in primary care requiring anticoagulant treatment. Routinely collected data are able to support this process but consistent coding of hypertension is important. Several factors may have contributed to the minor improvements demonstrated in this study. The NICE guideline of 2006 may have raised awareness of the benefits of this treatment. ${ }^{20}$ The BAFTA (Birmingham Atrial 
Fibrillation Treatment of the Aged) trial was published in 2007 and was reassuring over the risks/benefits of warfarin in older people with AF.31 A further factor was the introduction in 2006 of AF registers as part of the UK QOF, involving payments based on the proportion of people with AF treated with either anticoagulants or antiplatelet agents (irrespective of stroke risk level). From April 2012, the targets include the proportion of those with identified $\mathrm{CHADS}_{2}$ score $\geq 2$ who are receiving anticoagulant therapy. ${ }^{32}$

However, it is increasingly recognised that some patients with a $\mathrm{CHADS}_{2}$ score of 0-1 are at significant risk and would benefit from anticoagulation. Among those with $\mathrm{CHADS}_{2}=0$, the stroke/thromboembolism risk can vary between $0.84 \%$ /year (if the $\mathrm{CHA}_{2} \mathrm{DS}_{2}$-VASc score $=0$ ) to $3.2 \% /$ year (if the $\mathrm{CHA}_{2} \mathrm{DS}_{2}$-VASc score $=3$ ). ${ }^{33}$ Thus, a $\mathrm{CHADS}_{2}$ score of $0-1$ is not necessarily low risk' and only the $\mathrm{CHA}_{2} \mathrm{DS}_{2}$-VASc score can identify the truly low-risk group. The $\mathrm{CHADS}_{2} \geq 2$ threshold for determining anticoagulant uptake under the QOF is therefore an audit standard and not a definition of best practice.

A recent consensus statement from the
Royal College of Physicians of Edinburgh (RCPE) supports this conclusion, arguing for anticoagulation in all but the truly low-risk groups. ${ }^{34}$ According to the present survey results and their threshold, this would mean that around $91.6 \%$ of people with AF should be considered for this treatment. Strokes related to AF are associated with higher case fatality and more profound disability in survivors than non-AF related strokes, ${ }^{35}$ but could be minimised by this approach. As recommended in the European Society for Cardiology guidelines, ${ }^{6}$ risk scores have evolved to become more useful for identifying those at low risk (not requiring treatment) than those at high risk. ${ }^{36}$ The RCPE also recommends that, as aspirin is ineffective as thromboprophylaxis in $A F$, it should not be used for this reason alone. These developments have simplified decision-making policy and are likely to change practice significantly towards anticoagulation. Newer oral anticoagulants may potentially improve uptake still further. Future studies need to explore the remaining barriers, including the qualitative issues influencing patient-centred decision making over anticoagulation. 


\section{REFERENCES}

1. Go AS, Hylek EM, Phillips KA, et al. Prevalence of diagnosed atrial fibrillation in adults: national implications for rhythm management and stroke prevention: the AnTicoagulation and Risk Factors in Atrial Fibrillation (ATRIA) Study. JAMA 2001; 285(18): 2370-2375.

2. Gage BF, Waterman AD, Shannon W, et al. Validation of clinical classification schemes for predicting stroke. Results from the national registry of atrial fibrillation. JAMA 2001; 285(22): 2864-2870.

3. Olesen JB, Lip GY, Hansen ML, et al. Validation of risk stratification schemes for predicting stroke and thromboembolism in patients with atrial fibrillation: nationwide cohort study. BMJ 2001; 342: d124.

4. Stroke Risk in Atrial Fibrillation Working Group. Comparison of 12 risk stratification schemes to predict stroke in patients with nonvalvular atrial fibrillation. Stroke 2008; 39(6): 1901-1910.

5. Lip GY, Nieuwlaat R, Pisters R, et al. Refining clinical risk stratification for predicting stroke and thromboembolism in atrial fibrillation using a novel risk factor-based approach: the euro heart survey on atrial fibrillation. Chest 2010; 137(2): 263-272

6. Camm AJ, Kirchhof P, Lip GYH, et al, for the European Society for Cardiology. Guidelines for the management of atrial fibrillation. Eur Heart J 2010; 31(19): 2369-2429

7. Karthikeyan G, Eikelboom JW. The $\mathrm{CHADS}_{2}$ score for stroke risk stratification in atrial fibrillation - friend or foe? Thromb Haemost 2010; 104(1): 45-48.

8. Keogh C, Wallace E, Dillon C, et al. Validation of the $\mathrm{CHADS}_{2}$ clinical prediction rule to predict ischaemic stroke. A systematic review and meta-analysis. Thromb Haemost 2011; 106(3): 528-538.

9. Lip GYH, Halperin JL. Improving stroke risk stratification in atrial fibrillation. Am J Med 2010; 123(6): 484-488.

10. Hart RG, Pearce LA, Aguilar MI. Meta-analysis: antithrombotic therapy to prevent stroke in patients who have non-valvular atrial fibrillation. Ann Intern Med 2007; 146(12): 857-867.

11. Ogilvie IM, Newton N, Welner SA, et al. Underuse of oral anticoagulants in atrial fibrillation: a systematic review. Am J Med 2010; 123(7): 638-645e4

12. Nieuwlaat R, Capucci A, Lip GYH, et al, on behalf of the Euro Heart Survey Investigators. Antithrombotic treatment in real-life atrial fibrillation patients: a report from the Euro Heart Survey on Atrial Fibrillation. Eur Heart J 2006; 27(24): 3018-3026.

13. Sandhu RK, Bakal JA, Ezekowitz JA, McAlister FA. Risk stratification schemes, anticoagulation use and outcomes: the risk-treatment paradox in patients with newly diagnosed non-valvular atrial fibrillation. Heart 2011; 97(24): 2046-2050.

14. Majeed A, Moser K, Carroll K. Trends in the prevalence and management of atrial fibrillation in general practice in England and Wales, 1994-1998: analysis of data from the general practice research database. Heart 2001; 86(3): 284288.

15. Gallagher AM, Rietbrock S, Plumb J, van Staa TP. Initiation and persistence of warfarin or aspirin in patients with chronic atrial fibrillation in general practice: do the appropriate patients receive stroke prophylaxis? J Thrombosis Haemost 2008; 6(9): 1500-1506.

16. Van Staa TP, Setakis E, Di Tanna GL, et al. A comparison of risk stratification schemes for stroke in 79884 atrial fibrillation patients in general practice. J Thromb Haemost 2011; 9(1): 39-48.

17. NHS Improvement. Guidance on Risk Assessment and Stroke Prevention for Atrial Fibrillation (GRASP-AF). http://www.improvement.nhs.uk/graspaf/ laccessed 29 Aug 2012).

18. Quan H, Khan N, Hemmelgarn BR, et al. Validation of a case definition to define hypertension using administrative data. Hypertension 2009; 54(6): 1423e8.
19. Tu K, Campbell NRC, Chen Z-L, Cauch-Dudek KJ, McAlister FA. Accuracy of administrative databases in identifying patients with hypertension. Open Med 2007; 1(1): e18-e26.

20. National Institute for Health and Clinical Excellence. CG36: Atrial fibrillation. London: National Institute for Health and Clinical Excellence, 2006.

21. Hippisley-Cox J, Vinogradova Y, Coupland C, Pringle M. Comparison of key practice characteristics between general practices in England and Wales and general practices in the QResearch data. Report to the Health and Social Care Information Centre. Nottingham: University of Nottingham, 2005.

22. NHS The Information Centre. Quality and Outcomes Framework. http: //umw. qof.ic.nhs.uk/ (accessed 29 Aug 2012).

23. National Institute for Health and Clinical Excellence. CG127: Hypertension. The clinical management of primary hypertension in adults. London: National Institute for Health and Clinical Excellence, 2011.

24. Man-Son-Hing M, Nichol G, Lau A, Laupacis A. Choosing antithrombotic therapy for elderly patients with atrial fibrillation who are at risk for falls. Arch Intern Med 1999; 159(7): 677-685.

25. Gage BF,Cardinalli AB, Owens DK. The effect of stroke and stroke prophylaxis with aspirin or warfarin on quality of life. Arch Intern Med 1996; 156(16): 18291836

26. MacLean S, Mulla S, Akl EA, Jankowski M, et al. Patient values and preferences in decision making for antithrombotic therapy: a systematic review: Antithrombotic Therapy and Prevention of Thrombosis, 9th edn: American College of Chest Physicians Evidence-Based Clinical Practice Guidelines. Chest 2012; 141(2 suppl): e1S-23S.

27. Hollowell J, Ruigomez A, Johansson S, et al. The incidence of bleeding complications associated with warfarin treatment in general practice in the United Kingdom. Br J Gen Pract 2003; 53(489): 312-314.

28. Agarwal S, Hachamovitch R, Menon V. Current trial-associated outcomes with warfarin in prevention of stroke in patients with nonvalvular atrial fibrillation: a meta-analysis. Arch Intern Med 2012; 172(8): 623-631.

29. Olesen JB, Lip GYH, Lindhardsen J, et al. Risks of thromboembolism and bleeding with thromboprophylaxis in patients with atrial fibrillation: a net clinical benefit analysis using a 'real world' nationwide cohort study. Thromb Haemost 2011; 106(4): 739-749.

30. Baglin TP, Cousins D, Keeling DM, et al. Recommendations from the British Committee for Standards in Haematology and National Patient Safety Agency. Br J Haematol 2006; 136(1): 26-29.

31. Mant J, Hobbs FDR, Fletcher $\mathrm{K}$, et al. Warfarin versus aspirin for stroke prevention in atrial fibrillation in the elderly community population: the Birmingham Atrial Fibrillation Treatment of the Aged Study (BAFTA), a randomised controlled trial. Lancet 2007; 370(9586): 493-503.

32. Summary of 2012/13 QOF changes. http://wnw.nhsemployers.org/ SiteCollectionDocuments/Summary_of_QOF_changes_for_2012-13_mh111111. pdf laccessed 29 Aug 2012).

33. Olesen JB, Torp-Pedersen C, Hansen ML, Lip GY. The value of the $\mathrm{CHA}_{2} \mathrm{DS}_{2}$ VASc score for refining stroke risk stratification in patients with atrial fibrillation with a $\mathrm{CHADS}_{2}$ score 0-1: a nationwide cohort study. Thromb Haemost 2012; 107(6): 1172-1179.

34. Stott DJ, Dewar RI, Garratt CJ, et al. RCPE UK Consensus Conference on approaching the comprehensive management of atrial fibrillation: evolution or revolution?'. J R Coll Physicians Edinb 2012; 42(1): 34-35.

35. Lin H-J, Wolf PA, Kelly-Hayes M, et al. Stroke severity in atrial fibrillation: the Framingham study. Stroke 1996; 27(10): 1760-1764.

36. James MA, Campbell JL. Better prevention of stroke through screening for atrial fibrillation. Br J Gen Pract 2012; 62(598): 234-235. 